$$
\text { Artigos Originais }
$$




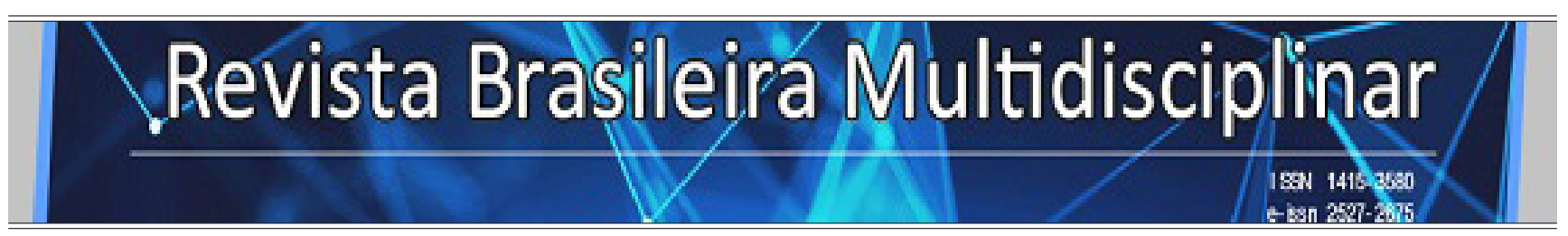

http://revistarebram.com/index.php/revistauniara

\title{
ANÁLISE ESTRUTURAL DE CONTÊINERES MARÍTIMOS UTILIZADOS NA CONSTRUÇÃo CIVIL
}

\author{
Flávio Teixeira de Souza*; Adelmo Magalhães de França Júnior**; Arlene Maria Cunha Sarmanho ${ }^{\star * *}$. \\ * Engenheiro Civil, Professor, Instituto Federal de Minas Gerais - Campus Ouro Preto. \\ ** Engenheiro Civil, Universidade Federal de Ouro Preto. \\ ${ }^{* * *}$ Engenharia da Civil, Professora, Universidade Federal de Ouro Preto/DECIV/EM.
}

*Autor para correspondência e-mail: flavio.souza@ifmg.edu.br

\section{Palavras-chave}

Contêineres Marítimos

Análise Numérica

Método dos Elementos Finitos

\section{KEYWORDS}

Shipping Containers Numerical Analysis Finite Element Method
Resumo: Uma possibilidade para a redução do déficit habitacional ou para a construção de habitações provisórias pode ser a utilização de contêineres marítimos descartados ao fim de sua vida útil na cadeia logística. Pela sua finalidade, os contêineres são estruturas robustas. No entanto, a arquitetura geralmente requer a inclusão de aberturas, a modificação das condições de apoio e o empilhamento dos contêineres, levando a condições de serviço diferentes das originalmente previstas. Este trabalho visa avaliar a influência destas modificações no comportamento estrutural dos contêineres. Para isto foi feita uma análise numérica via Método dos Elementos Finitos no programa comercial SAP2000, considerando aberturas e variações nas condições de apoio sob carregamento oriundo do empilhamento. Os resultados numéricos foram comparados a prescrições de normas brasileiras, e indicaram a viabilidade da utilização dos contêineres na construção civil na maioria das situações. No entanto, a combinação de grandes aberturas e modificações de suas condições de apoio leva a grandes deslocamentos e a elevadas concentrações de tensões, indicando a necessidade da adoção de medidas complementares para assegurar seu bom funcionamento estrutural.

\section{STRUCTURAL ANALYSIS OF SHIPPING CONTAINERS USED IN CIVIL CONSTRUCTION}

The use of shipping containers disposed after their utilization in logistics chain may be a possibility to decrease the lack of habitational units or for emergency housing. For their main destination, the containers have usually strong structures but, to be used in edifications, architecture commonly requires openings, support conditions and stacking that modify the original structure service conditions. This work aims to evaluate the influence of these modifications in containers structural behavior. This was carried out numerically by Finite Element Method in commercial software SAP2000, considering different openings layouts and support conditions under loading derived from stacking. The numerical results were compared to Brazilian codes prescriptions and indicated the viability of containers' utilization in civil construction. However, the combination of large openings and severe support condition modification leads to large displacement and stresses in containers, suggesting the need of reinforcements to assure their structural performance. 


\section{INTRODUÇão}

A escassez de recursos e a especulação imobiliária têm elevado o custo das habitações. Uma das alternativas é a aplicação do contêiner marítimo à construção civil, pois sua capacidade de modulação possibilita diversos arranjos arquitetônicos, isoladamente ou combinado a outros sistemas construtivos. Contudo, por ser uma técnica construtiva recente, têm sido desenvolvidos estudos para aperfeiçoar a utilização dos contêineres em edificações (ZOMER, 2009; MARQUES, 2011).

Define-se contêiner marítimo como todo dispositivo metálico utilizado para armazenar, conservar e transportar mercadorias. Em geral sua vida útil na cadeia logística é de dez anos, gerando um passivo ambiental após este período (MILANEZE et al., 2012). Os contêineres são padronizados pela Organização Internacional de Padronização (ISO) (SMITH, 2010). Conforme as normas ISO 6346 (ISO, 1995), ISO 668 (ISO, 2013) e ISO 1496-1 (ISO, 2013), os contêineres marítimos são classificados em função de seu tamanho e destinação. De todos eles, os mais utilizados para a construção civil são os contêineres de uso geral e uso geral de teto alto, com tamanho de 20 e 40 pés, apresentados na Tabela 1, cujas dimensões são apresentadas na Tabela 2.

De acordo com Romano, Paris e Neuenfeldt (2014), antes de optar pela utilização de contêineres na construção civil devem-se avaliar suas vantagens e desvantagens. As principais vantagens são sua robustez estrutural, alta resistência à corrosão, dimensões padronizadas, baixo custo de aquisição, agilização do cronograma e a redução de resíduos. Suas desvantagens são a falta de isolamento termo-acústico, exigência de profissionais e equipamentos especializados, alto custo de transporte a longas distâncias e o risco de contaminações de diversos tipos dependendo de seu uso anterior.

A construção utilizando contêineres é bastante versátil, podendo ser utilizada em residências, hotéis, escritórios, lojas, bares ou restaurantes e espaços públicos. A Figura 1 apresenta exemplos de aplicação de contêineres em edificações. Os contêineres são também utilizados com êxito na construção de habitações provisórias em caso de desastres (ZHANG; SETUNGE; VAN ELMPT, 2014; HONG, 2017).

Tabela 1 - Tipos de contêineres.

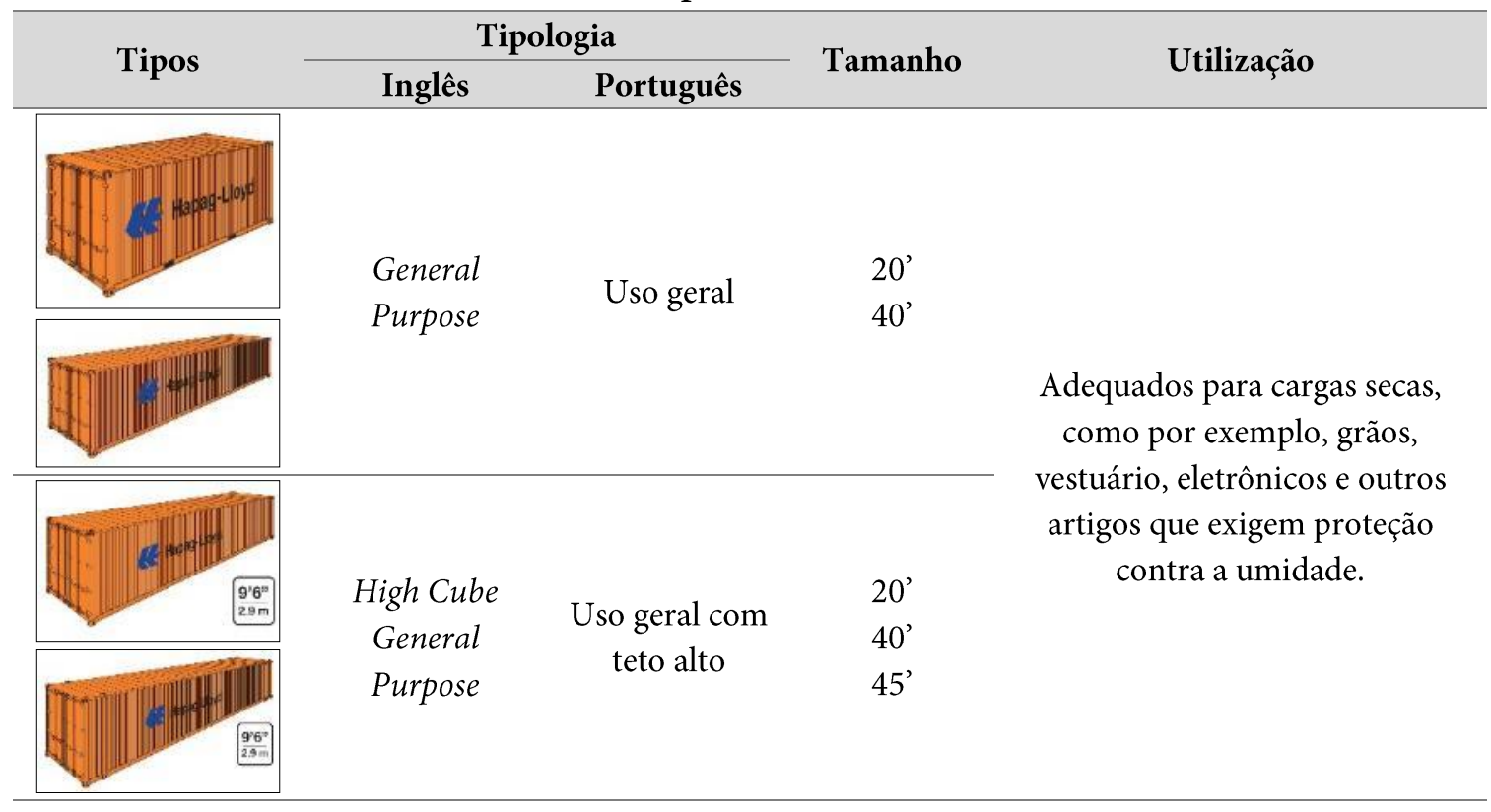

Fonte: HAPAG-LLOYD, 2016. 
Tabela 2 - Padronização das medidas dos contêineres.

\begin{tabular}{|c|c|c|c|c|c|}
\hline & \multicolumn{2}{|c|}{ Comprimento } & \multirow{2}{*}{$\begin{array}{c}\text { Largura } \\
8^{\prime}\end{array}$} & \multicolumn{2}{|c|}{ Altura } \\
\hline \multirow{2}{*}{ Dimensões Externas } & $20^{\prime}$ & $40^{\prime}$ & & $8^{\prime} 6^{\prime \prime}$ & 9' 6" \\
\hline & $6058 \mathrm{~mm}$ & $12192 \mathrm{~mm}$ & $2438 \mathrm{~mm}$ & $2591 \mathrm{~mm}$ & $2896 \mathrm{~mm}$ \\
\hline \multirow{2}{*}{$\begin{array}{l}\text { Dimensões Mínimas In- } \\
\text { ternas }\end{array}$} & $19^{\prime} 3^{\prime \prime}$ & $39^{\prime} 4^{3 / 8^{\prime \prime}}$ & $7^{\prime} 7^{3 / 4 \prime}$ & $7^{\prime} 8^{1 / 2 \prime \prime}$ & $8^{\prime} 8^{1 / 2 \prime \prime}$ \\
\hline & $5867 \mathrm{~mm}$ & $11998 \mathrm{~mm}$ & $2330 \mathrm{~mm}$ & $2350 \mathrm{~mm}$ & $2655 \mathrm{~mm}$ \\
\hline \multirow{2}{*}{$\begin{array}{l}\text { Dimensões Mínimas da } \\
\text { Abertura das Portas }\end{array}$} & \multirow{2}{*}{-} & \multirow{2}{*}{-} & $7^{\prime} 6^{\prime \prime}$ & $7^{\prime} 5^{\prime \prime}$ & $8^{\prime} 5^{\prime \prime}$ \\
\hline & & & $2286 \mathrm{~mm}$ & $2261 \mathrm{~mm}$ & $2566 \mathrm{~mm}$ \\
\hline
\end{tabular}

Fonte: HAPAG-LLOYD, 2016.

Figura 1- Exemplos de aplicações para o contêiner marítimo na construção civil, em sentido horário a partir do canto superior esquerdo: Casa Container Granja Viana, Tetris Hostel, Freitag Flagship Zurich, Muv Box Fastfood Container Restaurant, The Box Office.
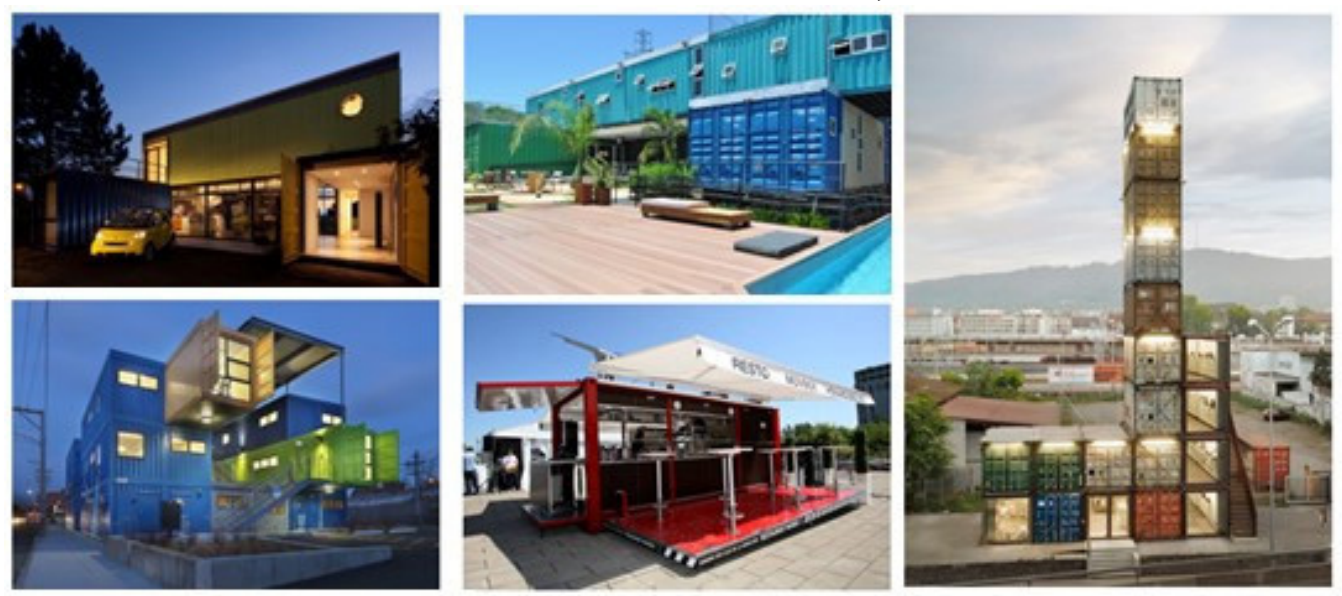

Fontes: ARCHDAILY (2016); CASA CLÁUDIA (2016); SPILLMANN ECHSLE ARCHITEKTEN (2016); INHABITAT (2016a; 2016b).

O comportamento estrutural de contêineres na construção civil ainda é pouco estudado. Como eles são projetados para suportar elevados carregamentos, pressupõe-se que as cargas correntes em edificações serão bem absorvidas pela estrutura. No entanto, a necessidade de adaptações como aberturas e mudança nas condições de apoio impostas pela arquitetura podem modificar sensivelmente o comportamento estrutural do contêiner. Atualmente, o uso de ferramentas numéricas tem sido importante para a análise do comportamento e da resistência de contêineres marítimos utilizados na construção civil. (GIRIUNAS; SEZEN; DUPAIX, 2012; BERNARDO et al., 2013).

\section{OвJETivo}

Este trabalho tem o objetivo de avaliar os efeitos das aberturas, da introdução de balanços e do empilhamento na estrutura de contêineres marítimos utilizados na construção civil, a partir da análise da distribuição de tensões nas chapas de fechamento e da comparação de esforços solicitantes nos elementos estruturais com resultados obtidos pelas normas NBR 8800 - Projeto de estruturas de aço e de estruturas mistas de aço e concreto de edifícios (ABNT, 2008) e NBR 14762 - Dimensionamento de Estruturas de 
Aço Constituídas por Perfis Formados a Frio (ABNT, 2010).

\section{Metodologia}

\section{DESCRIÇÃO dA ESTRUTURA do CONTÊINER}

A estrutura do contêiner é composta por elementos reticulados compostos por perfis metálicos e por fechamentos de chapas de seção trapezoidal (SILVA, 2010), conforme apresentado na Figura 2. Os elementos reticulados têm seções diferentes das seções comerciais, conforme apresentado na Tabela 3.
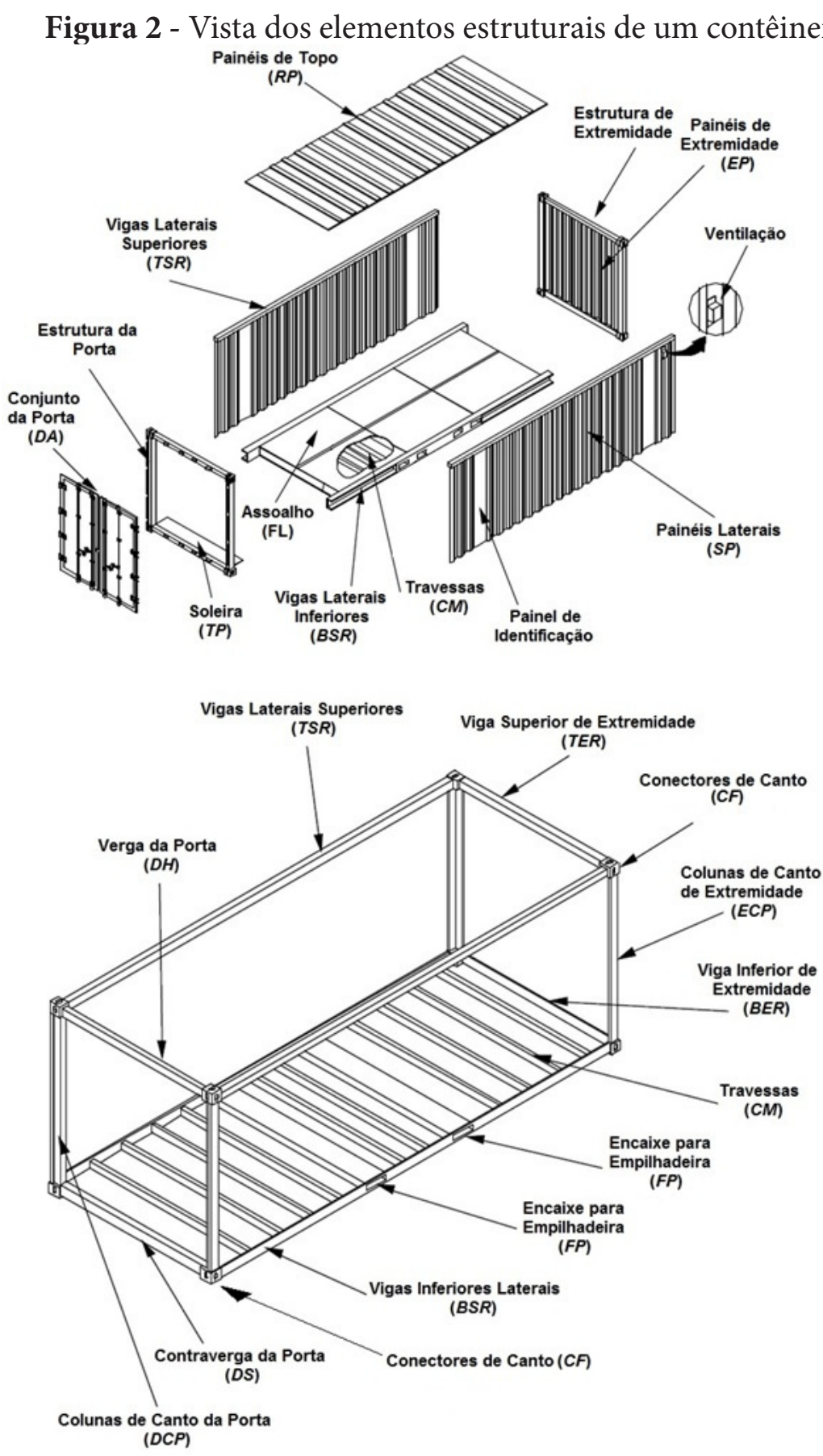

Fonte: Adaptado de Residential Shipping Container Primer (2016). 
Tabela 3 - Principais elementos da estrutura de um contêiner marítimo.

\begin{tabular}{|c|c|c|c|}
\hline Elemento & Sigla & Figura & Seção Transversal (mm) \\
\hline $\begin{array}{l}\text { Colunas de canto da } \\
\text { porta (externo) }\end{array}$ & & 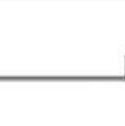 & $\begin{array}{c}\text { Perfil30 x } 230 \times 46 \times 56 \\
t=6,0\end{array}$ \\
\hline $\begin{array}{l}\text { Colunas de canto da } \\
\text { porta (interno) }\end{array}$ & & & Perfil U 114 x 40 x 12 \\
\hline Verga da porta & DH & & $\begin{array}{l}\text { Tubo } 110 \times 138 \\
t=4,0\end{array}$ \\
\hline Contra-verga da porta & DS & & $\begin{array}{l}\text { Perfil } 65 \times 140 \times 115 \times 31 \times 50 \\
t=4,5\end{array}$ \\
\hline $\begin{array}{l}\text { Colunas de canto de } \\
\text { extremidade }\end{array}$ & $\mathrm{ECP}$ & ل & $\begin{array}{c}\text { Perfil } 56 \times 46 \times 174 \times 159 \times 55 \times \\
56 \\
t=6,0\end{array}$ \\
\hline $\begin{array}{l}\text { Viga superior de extre- } \\
\text { midade }\end{array}$ & TER & & $\begin{array}{l}\text { Tubo Quadrado } 60 \times 62 \\
\qquad \mathrm{t}=3,2\end{array}$ \\
\hline $\begin{array}{l}\text { Viga inferior de extre- } \\
\text { midade }\end{array}$ & BER & $\widetilde{r}$ & $\begin{array}{c}\text { Perfil } 44 \times 152 \times 59 \times 34,5 \times 49 \\
t=4,4\end{array}$ \\
\hline $\begin{array}{l}\text { Vigas inferiores late- } \\
\text { rais }\end{array}$ & BSR & L & $\begin{array}{l}\text { Perfil C } 30 \times 162 \times 48 \\
t=6,0\end{array}$ \\
\hline Travessas & $\mathrm{CM}$ & $\beth$ & $\begin{array}{l}\text { Perfil C } 45 \times 122 \times 45 \\
\qquad t=4,5\end{array}$ \\
\hline
\end{tabular}

Fonte: Adaptado de Bernardo et al. (2013).

\section{Análise Computacional}

Em geral, o comportamento estrutural de um contêiner deve ser analisado em função das características arquitetônicas da edificação, que induzem na estrutura solicitações de esforços provenientes de empilhamento, ação do vento, vãos em balanço e aberturas em seus painéis.

A análise numérica desenvolvida neste trabalho teve o objetivo de simular a estrutura do contêiner marítimo utilizada na construção civil. Foi utilizado o programa comercial SAP2000 (CSI, 2017).

\section{GEOMETRIA E PROPRIEDADES DOS MATERIAIS}

A geometria de um contêiner é complexa, uma vez que se trata de uma estrutura composta por perfis de diversas seções diferentes e por chapas de aço que contribuem para a estabilidade da estrutura. A geração da geometria foi feita em CAD, e posteriormente importada para o SAP2000, conforme mostra a Figura 3, em que pode-se observar, pela diferença de tonalidade, as regiões em que a chapa tem $2 \mathrm{~mm}$ de espessura e a região central dos painéis laterais, em tom mais claro, em que as chapas têm 1,6 mm de 
espessura. Foram ainda atribuídas as seções dos elementos reticulados da estrutura, conforme apresentado na Tabela 3.

Figura 3 - Geometria gerada em CAD.
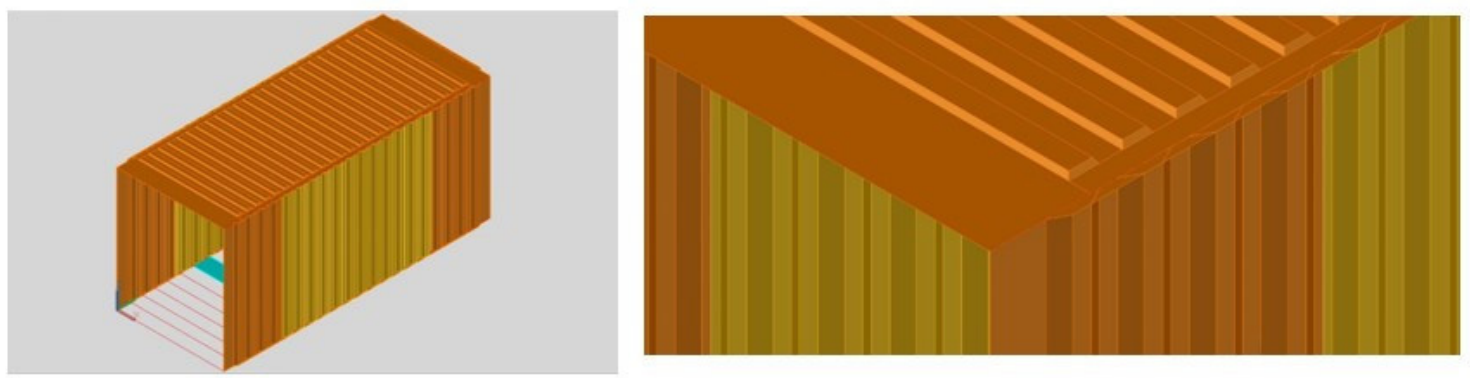

Fonte: Elaborada pelos autores.

Na Tabela 4 têm-se as características mecânicas dos materiais empregados nos diversos elementos que compõem o modelo. A consideração da madeira para o piso é fundamental devido ao efeito deste componente na estabilidade do sistema. Suas propriedades foram obtidas considerando as prescrições da norma NBR 7190 - Projetos de estruturas de madeira (ABNT, 1997).

Tabela 4 - Propriedades mecânicas dos materiais atribuídos ao modelo computacional

\begin{tabular}{c|c|c|c|c|c}
\hline Material & Utilização & $\begin{array}{c}\text { Peso Específi- } \\
\mathbf{c o}\left(\mathbf{k N} / \mathbf{m}^{\mathbf{3}}\right)\end{array}$ & $\begin{array}{c}\text { Módulo de } \\
\text { Elasticidade } \\
(\mathbf{M P a})\end{array}$ & $\begin{array}{c}\text { Tensão de } \\
\text { Escoamento } \\
(\mathbf{M P a})\end{array}$ & $\begin{array}{c}\text { Tensão Última } \\
\mathbf{( M P a})\end{array}$ \\
\hline $\begin{array}{c}\text { Aço anticorro- } \\
\text { sivo }\end{array}$ & $\begin{array}{c}\text { Chapas e } \\
\text { perfis }\end{array}$ & 7,85 & 200.000 & 350 & 490 \\
\hline Aço & $\begin{array}{c}\text { Perfis Lami- } \\
\text { nados }\end{array}$ & 7,85 & 200.000 & 330 & 500 \\
\hline Madeira & Piso & 0,50 & 3.500 & N.A. & N.A. \\
\hline
\end{tabular}

Fonte: Elaborada pelos autores.

\section{MALHA DE ELEMENTOS Finitos}

Na modelagem do contêiner, consideraram-se dois tipos de elementos. Para a simulação dos elementos reticulados, foram utilizados elementos de barra e para a simulação dos fechamentos, elementos de casca da biblioteca do SAP2000.

Segundo CSI (2007), os elementos de barra podem simular vigas, colunas, contraventamentos, treliças e estruturas planas ou tridimensionais. A formulação considera os efeitos de flexão biaxial, torção, deformação axial e deformações de cisalhamento biaxial. Cada elemento possui seu próprio sistema local de coordenadas, definindo propriedades de seções e carregamentos. Os elementos de casca são utilizados para modelar o comportamento de uma membrana, placa ou casca em estruturas planas ou tridimensionais, sendo que o material atribuído pode ser homogêneo ou disposto em camadas de acordo com a espessura atribuída. Possuem uma formulação de três ou quatro nós que considera o comportamento de flexão no elemento.

O refinamento da malha dos elementos de casca foi feito buscando aliar resultados confiáveis a um tempo de processamento adequado. Foram adotados elementos quadrilaterais de $100 \mathrm{~mm}$ de lado. A Figura 4 apresenta a malha de elementos finitos. 
Figura 4 - Malha de elementos finitos gerada no SAP.

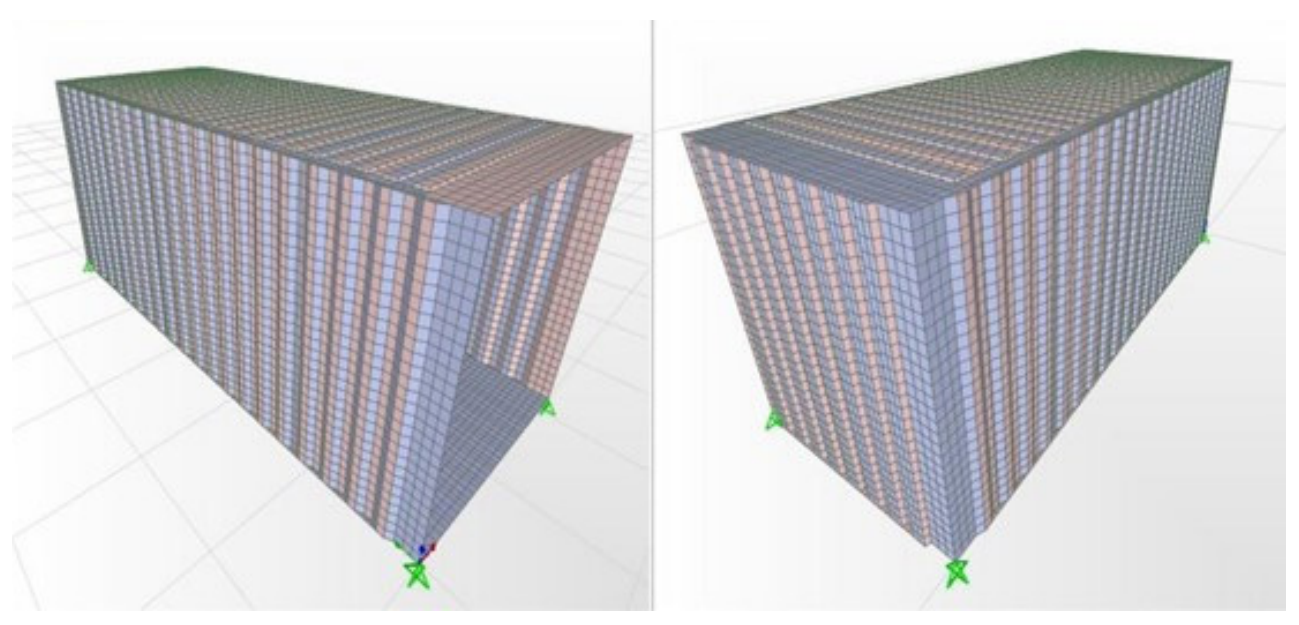

Fonte: Elaborada pelos autores.

\section{CONDIÇõES DE APOIO E ABERTURAS NAS FACES LATERAIS}

Foram desenvolvidos quatro modelos computacionais com variações de condições de apoio e de aberturas, indicados na Tabela 5, com a finalidade de verificar a influência destas alterações no comportamento da estrutura.

Tabela 5 - Aberturas e condições de apoio nos modelos.

\begin{tabular}{llll}
\hline & Aberturas & Apoios & Sigla \\
\cline { 2 - 3 } Contêiner 20' High Cube & Sem aberturas & $\begin{array}{l}\text { Extremida- } \\
\text { des }\end{array}$ & SA-E \\
\cline { 2 - 3 } & Com aberturas & $\begin{array}{l}\text { Extremida- } \\
\text { des }\end{array}$ & SA-B \\
\cline { 2 - 3 } & CA-E \\
\hline
\end{tabular}

Fonte: Elaborada pelos autores.

Adotaram-se dois tipos de condições de apoio. A primeira condição de apoio representa o contêiner apoiado diretamente aos conectores de canto inferiores, como mostra com a Figura 5. A segunda condição de apoio representa um contêiner em balanço, conforme apresentado na Figura 6. Nesta situação, foram posicionados apoios nas vigas laterais inferiores, a fim de simular o efeito da disposição dos contêineres perpendicularmente entre si.

Com relação às aberturas laterais, foram consideradas duas situações. Na primeira, consideraram-se as faces sem nenhuma abertura, tal qual ocorre com o contêiner em sua aplicação original. Na segunda, consideraram-se aberturas de cada lado do contêiner com 3,30 m de largura e altura do piso ao teto. Conforme ressaltado em Silva (2010), esta largura corresponde à chapa de 1,6 $\mathrm{mm}$ de espessura localizadas na região central do painel lateral (Figura 3). Sendo assim, as regiões das chapas laterais com 2,0 mm de espessura permaneceram na estrutura com o objetivo de preservar uma parte da rigidez do conjunto. 
Figura 5 - Contêiner apoiado nos conectores de canto.
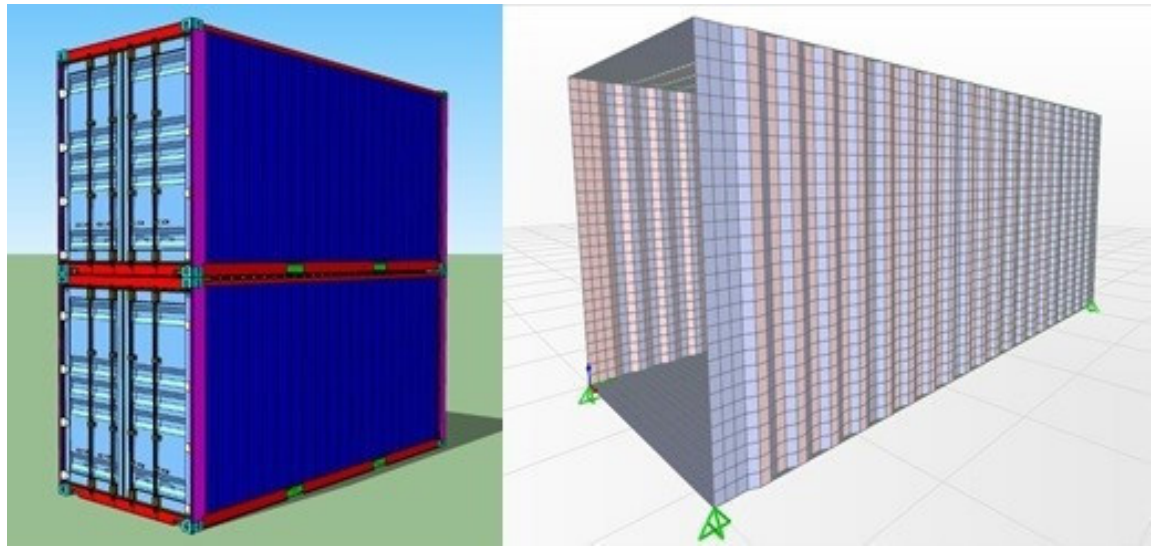

Fonte: Elaborada pelos autores.

Figura 6 - Contêiner em balanço.
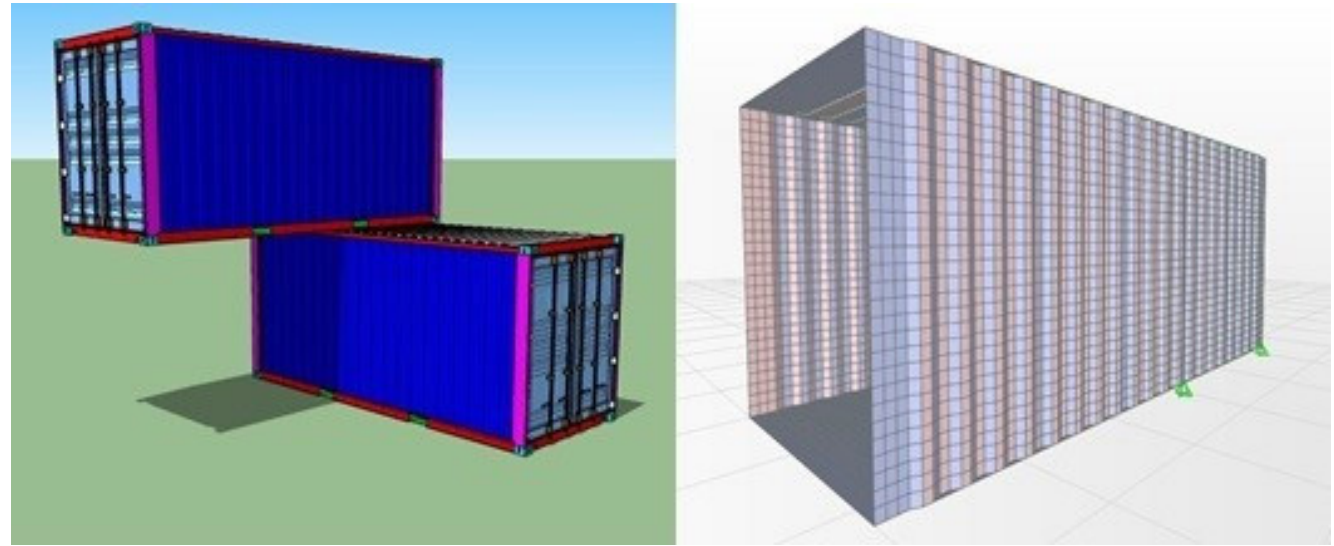

Fonte: Elaborada pelos autores.

\section{Carregamento aplicado}

A simulação numérica realizada considerou os contêineres marítimos submetidos a carregamentos de edificações, ou seja, cargas diferentes daquelas para as quais as estruturas são originalmente concebidas. Desta fora, consideraram-se as cargas e combinações previstas nas seguintes normas:

NBR 6120 (ABNT, 1980) - Cargas para o cálculo de estruturas de edificações;

NBR 6123 (ABNT, 1988) - Forças devido ao vento em edificações;

NBR 8800 (ABNT, 2008) - Projeto de estruturas de aço e de estruturas mistas de aço e concreto de edifícios.

As cargas permanentes consideraram o peso dos elementos do contêiner, e as cargas acidentais consideraram a situação mais desfavorável, ou seja, ambientes com acesso ao público $\left(\mathrm{q}=4 \mathrm{kN} / \mathrm{m}^{2}\right)$. Foram considerados carregamentos diferentes para cada condição de apoio apresentada no item 3.3, considerando a real situação de serviço do contêiner. O contêiner apoiado nos quatro conectores de canto foi considerado como o primeiro de uma série de oito elementos empilhados, sendo este o limite previsto de empilhamento (ISO, 2013). As cargas verticais foram aplicadas de forma concentrada aos conectores de canto (CF), transferindo-se assim às colunas de canto (ECP e DCP). Foram consideradas as cargas de vento atuantes na estrutura de andares múltiplos, transferidas para as colunas de canto por efeito do 
binário que exercem sobre a estrutura (Bellei, 2008). A Tabela 6 apresenta as cargas aplicadas no contêiner apoiado nos quatro conectores de canto.

Tabela 6 - Cargas aplicadas ao modelo apoiado nos quatro conectores de canto.

\begin{tabular}{llll}
\hline Permanente $(\mathrm{kN})$ & Acidental $(\mathrm{kN})$ & Vento $0^{\circ}(\mathrm{kN})$ & Vento $90^{\circ}(\mathrm{kN})$ \\
\hline 66,85 & 112,37 & 886,82 & 100,11 \\
\hline
\end{tabular}

Fonte: elaborada pelos autores.

O container em balanço foi considerado apoiado no oitavo pavimento da edificação, por ser esta a situação mais desfavorável em relação à carga de vento. Além desta ação, foi também considerado o peso próprio do contêiner e a carga acidental. A Tabela 7 apresenta as cargas aplicadas ao contêiner em balanço.

Tabela 7 - Cargas aplicadas ao modelo em balanço.

\begin{tabular}{llll}
\hline Permanente $(\mathrm{kN})$ & Acidental $(\mathrm{kN})$ & Vento $0^{\circ}(\mathrm{kN})$ & Vento $90^{\circ}(\mathrm{kN})$ \\
\hline 8,36 & 14,05 & 181,72 & 20,56 \\
\hline
\end{tabular}

Fonte: Elaborada pelos autores.

Foram consideradas as seguintes combinações de cargas (ABNT, 2008):

$\mathrm{C} 1=1,4 \mathrm{CP}+1,5 \mathrm{CA}$ (Normal)

$\mathrm{C} 2=1,4 \mathrm{CP}+1,5 \mathrm{CA}+0,84 \mathrm{~V}_{0}\left(\right.$ Vento a $\left.0^{\circ}\right)$

$\mathrm{C} 3=1,4 \mathrm{CP}+1,5 \mathrm{CA}+0,84 \mathrm{~V}_{90}\left(\right.$ Vento a $\left.90^{\circ}\right)$

\section{RESUlTAdos E Discuss Ão}

Para análise dos resultados obtidos através das simulações, serão consideradas as tensões de von Mises e os deslocamentos nas chapas trapezoidais do fechamento, além dos esforços solicitantes e deslocamentos nas vigas e colunas da estrutura. Serão apresentados os resultados obtidos para as quatro situações apresentadas na Tabela 5.

\section{Contêiner SEM Aberturas, APOIOS NAS EXTREmidades (SA-E)}

A Figura 7 apresenta os deslocamentos da direção transversal ao contêiner. Observam-se deslocamentos máximos de 1,53 mm na porção central dos painéis laterais (SP), em direção ao interior do contêiner, e nas porções laterais destes mesmos painéis ocorre o deslocamento de $1,25 \mathrm{~mm}$, de dentro para fora. $\mathrm{O}$ painel de extremidade (EP) não teve deslocamentos transversais significativos nesta direção.

A Figura 8 apresenta os deslocamentos verticais do contêiner. A porção central do painel de topo (RP) apresenta deslocamento da ordem de $3 \mathrm{~mm}$, para dentro. Observam-se, nas duas direções, deslocamentos relativamente pequenos. Isto deve-se ao contêiner utilizado na construção civil estar submetido a carregamentos inferiores àqueles para os quais foram projetados.

Foram ainda avaliados os esforços solicitantes nos elementos de barra. Estes valores são apresentados na Tabela 8, juntamente aos limites determinados pelas normas brasileiras NBR 8800 (ABNT,2008) para o elemento laminado (coluna da porta) e pela NBR 14762 (ABNT, 2010) para os demais elementos formados a frio. Neste caso, foi utilizado o Método da Resistência Direta e a análise de estabilidade via Teoria Generalizada de Vigas (GBT) pelo software GBTul (Bebiano et al, 2008). Observa-se neste caso, que todos os elementos apresentam solicitações inferiores às resistências determinadas normativamente, 
além de deslocamentos dentro dos limites previstos.

O mesmo ocorre quando se analisam as tensões de von Mises. Os maiores valores são da ordem de $90 \mathrm{MPa}$, conforme apresentado na Figura 9.

Figura 7- Deslocamentos na direção transversal do contêiner SA-E (mm).
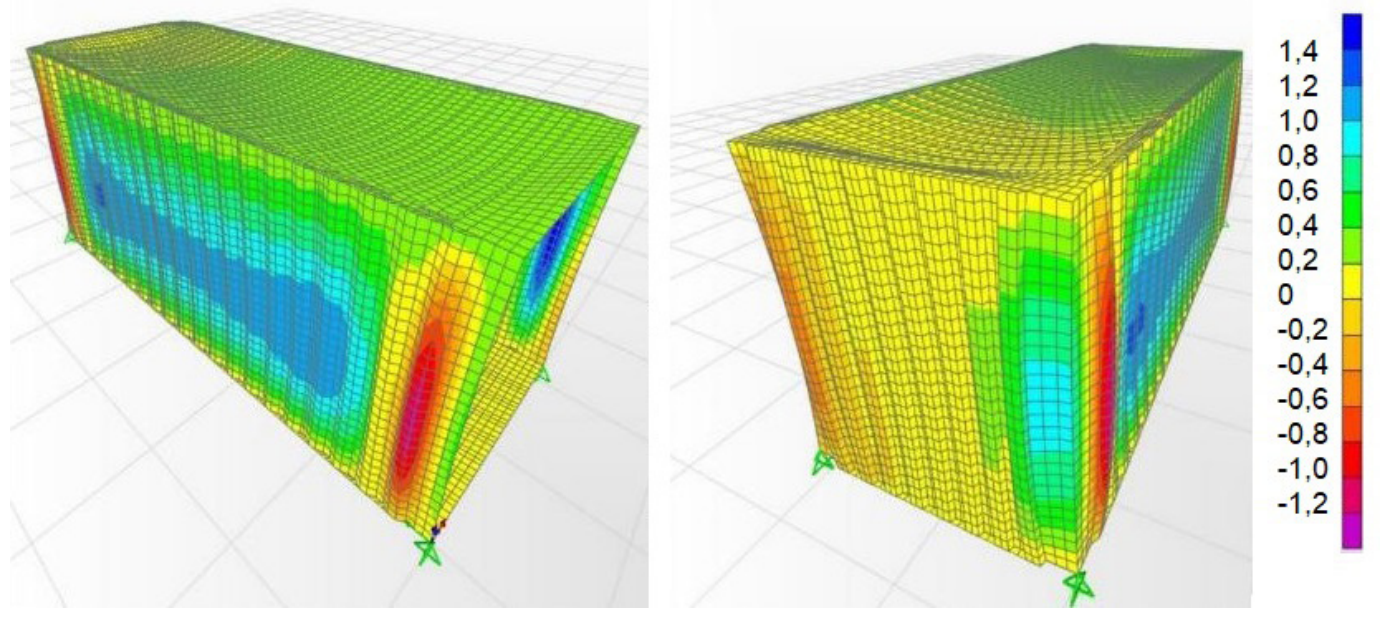

Fonte: Elaborada pelos autores.

Figura 8 - Deslocamentos na direção vertical do contêiner SA-E (mm).
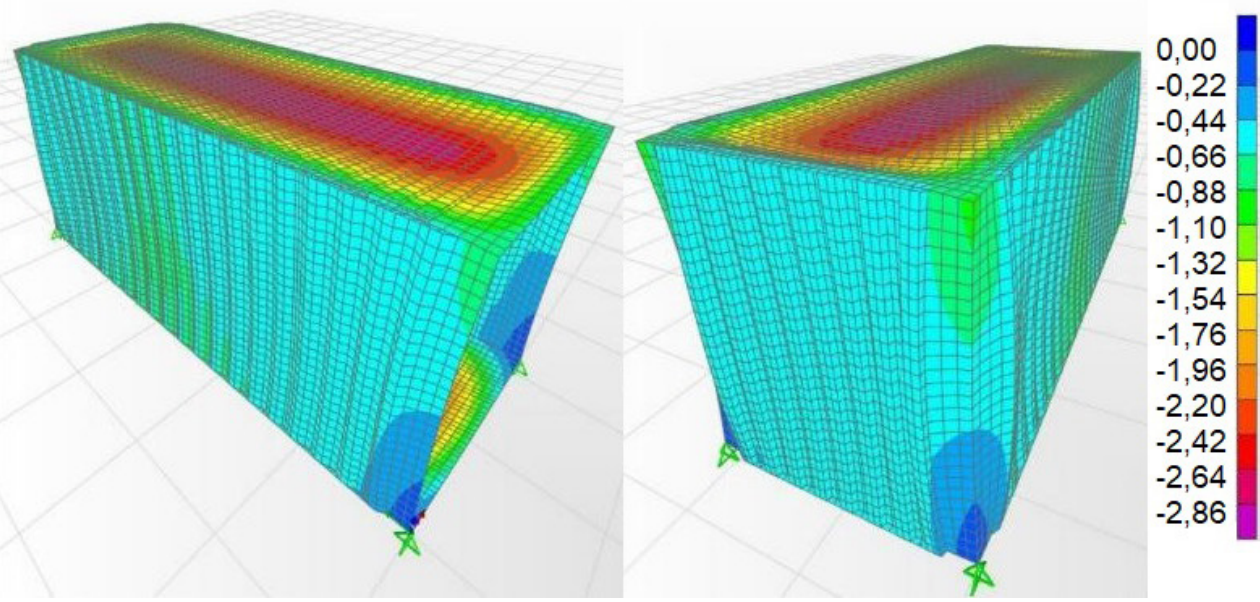

Fonte: Elaborada pelos autores. 
Figura 9 - Tensões de von Mises no contêiner SA-E (MPa).
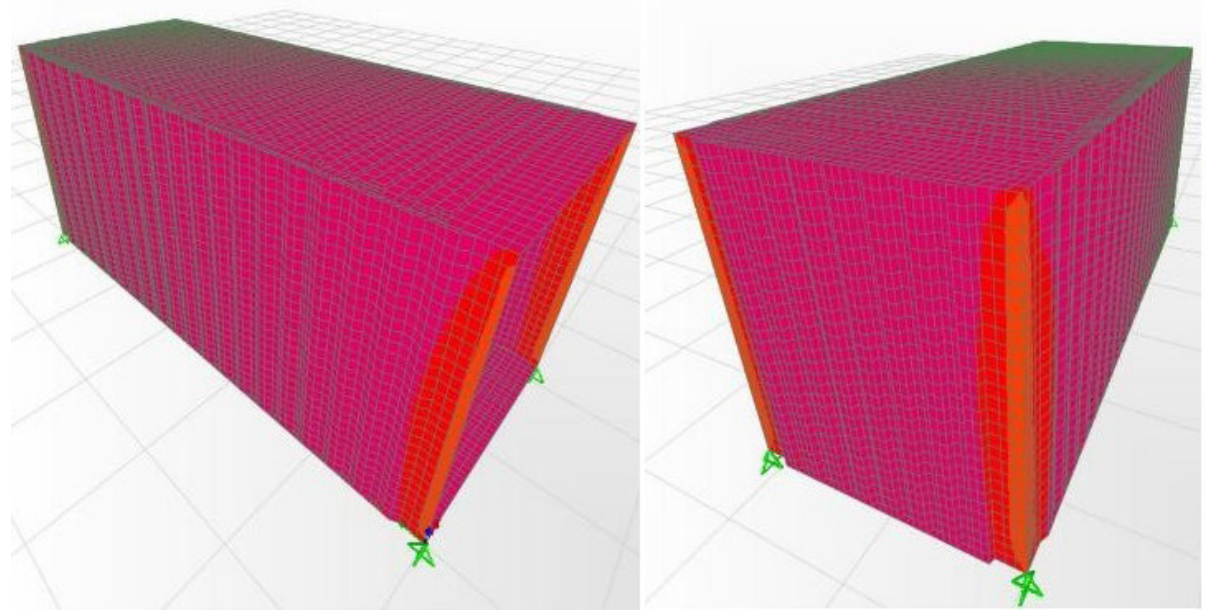

Fonte: Elaborada pelos autores.

Tabela 8 - Esforços solicitantes para o contêiner SA-E.

\begin{tabular}{|c|c|c|c|c|}
\hline ELEMENTO ESTRUTURAL & C1 & $\mathrm{C} 2$ & C3 & Normas \\
\hline \multicolumn{5}{|l|}{ ESFORÇOS AXIAIS NAS COLUNAS (kN) } \\
\hline Coluna de canto da porta (DCP) & $-265,89$ & $-266,56$ & $-269,70$ & $-482,5$ \\
\hline Coluna de canto da extremidade (ECP) & $-240,50$ & $-251,78$ & $-243,63$ & $-970,8$ \\
\hline \multicolumn{5}{|c|}{ MOMENTOS FLETORES NAS VIGAS (kN.mm) } \\
\hline Viga lateral superior (TSR) & 635,10 & 634,49 & 629,13 & 4635 \\
\hline Viga lateral inferior (BSR) & $-1652,49$ & 1661,61 & $-1715,52$ & 14523 \\
\hline \multicolumn{5}{|l|}{ DESLOCAMENTOS NAS VIGAS (mm) } \\
\hline Viga lateral inferior (BSR) & 0,99 & 1,01 & 0,99 & 17,3 \\
\hline Viga lateral superior (TSR) & 0,72 & 0,76 & 0,75 & 17,3 \\
\hline
\end{tabular}

Fonte: Elaborada pelos autores.

\section{CONTÊINER SEM ABERTURAS, EM BALANÇo (SA-B)}

A Figura 10 apresenta os deslocamentos na direção transversal ao contêiner. Observa-se um acréscimo nos deslocamentos em relação ao contêiner apoiado nas extremidades, ou seja, $8,55 \mathrm{~mm}$, de dentro para fora, nos painéis laterais, na região em que os apoios são aplicados nas vigas inferiores laterais (BSR). O painel de extremidade (EP) praticamente não teve deslocamentos transversais.

A Figura 11 apresenta os deslocamentos verticais observados no contêiner em balanço. Observa-se um deslocamento da ordem de $4 \mathrm{~mm}$ em sua extremidade, próxima à abertura da porta. No entanto, este deslocamento é próximo àqueles do contêiner apoiado nas extremidades, indicando o importante efeito estabilizador das chapas trapezoidais.

Foram ainda analisados os esforços e deslocamentos nas vigas e colunas do contêiner em balaço, apresentadas na Tabela 9. Observa-se que, se comparado ao caso anterior, os esforços axiais na coluna são de tração, ao passo que os momentos fletores nas vigas são maiores, apesar do menor carregamento aplicado. Assim como no primeiro caso, as solicitações e deslocamentos estão dentro dos limites previstos pelas normas. 
Figura 10 - Deslocamentos na direção transversal do contêiner SA-B (mm).

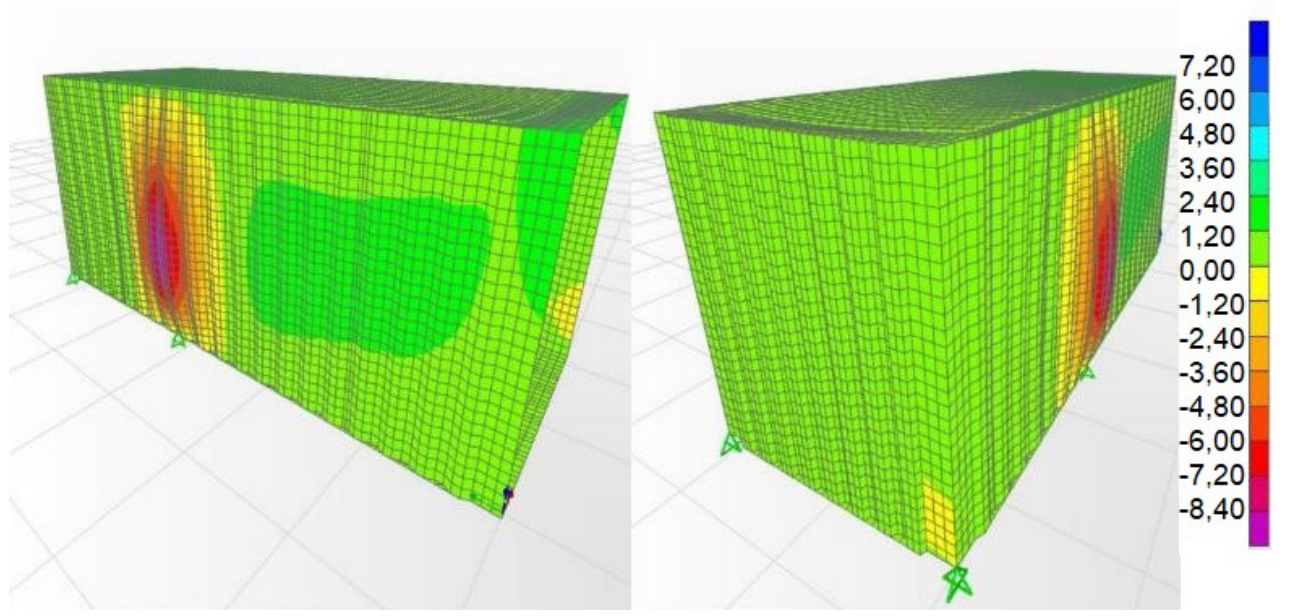

Fonte: Elaborada pelos autores.

Figura 11 - Deslocamentos na direção vertical do contêiner SA-B (mm).
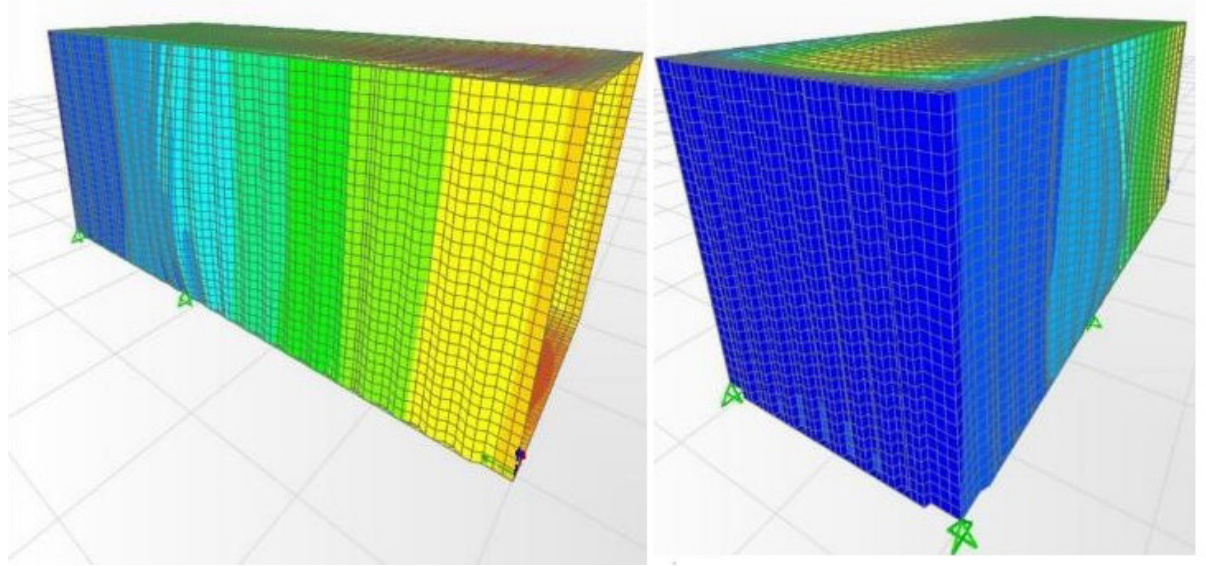

0,00

$-0,30$

$-0,60$

$-0,90$

$-1,20$

$-1,50$

$-1,80$

$-2,10$

$-2,40$

$-2,70$

$-3,00$

$-3,30$

$-3,60$

$-3,90$

Fonte: Elaborada pelos autores.

Foi observada uma concentração de tensões nos painéis laterais, na região em que os apoios foram aplicados nas vigas laterais inferiores, com valores chegando a $165 \mathrm{MPa}$, conforme mostra a Figura 12. Apesar de elevado em relação ao caso anterior, este valor das tensões ainda é inferior ao limite de escoamento do aço empregado (Tabela 4). 
Figura 12- Tensões de von Mises no contêiner SA-B (MPa).

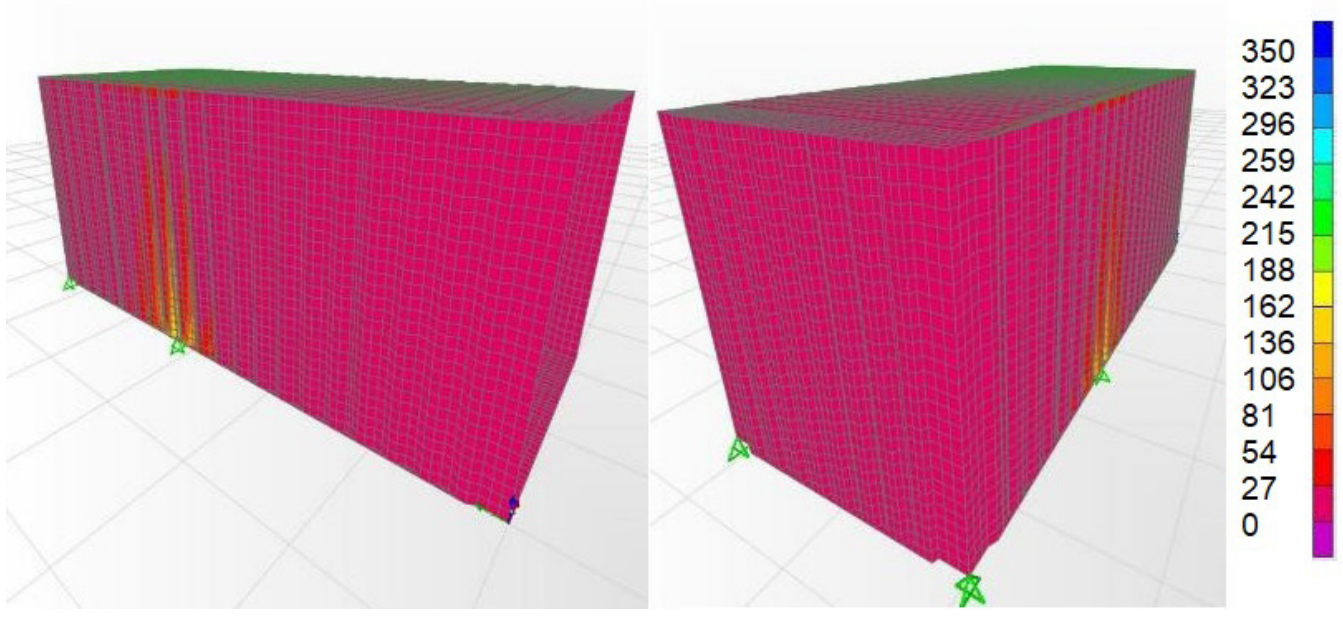

Fonte: Elaborada pelos autores.

Tabela 9 - Esforços solicitantes para o contêiner SA-B.

\begin{tabular}{|lllll|}
\hline ELEMENTO ESTRUTURAL & C1 & C2 & C3 & Normas \\
\hline ESFORÇOS AXIAIS NAS COLUNAS (kN) & & & & \\
\hline Coluna de canto da porta (DCP) & 2,79 & 3,2 & 2,96 & $-482,5$ \\
\hline Coluna de canto da extremidade (ECP) & 12,18 & 29,37 & 14,76 & $-970,8$ \\
\hline MOMENTOS FLETORES NAS VIGAS (kN.mm) & \multicolumn{5}{l}{} \\
\hline Viga lateral superior (TSR) & 154,59 & 196,73 & 177,98 & 4635 \\
\hline Viga lateral inferior (BSR) & $-6347,85$ & $-8071,75$ & $-7354,14$ & 14523 \\
\hline DESLOCAMENTOS NAS VIGAS (mm) & & & & \\
\hline Viga lateral inferior (BSR) & 2,15 & 2,8 & 2,52 & 17,3 \\
\hline Viga lateral superior (TSR) & 2,15 & 2,8 & 2,52 & 17,3 \\
\hline
\end{tabular}

Fonte: Elaborada pelos autores.

\section{Contêiner com aberturas, Apoio nas eXtremidades (CA-E)}

Neste item apresentam-se os resultados do contêiner com aberturas, apresentado no item 3.3, com o mesmo carregamento e apoios do item 4.1. Este modelo obteve um deslocamento transversal ao contêiner superior a $22 \mathrm{~mm}$ na região da porta, conforme mostra a Figura 13. 
Figura 13 - Deslocamentos na direção transversal do contêiner CA-E (mm).

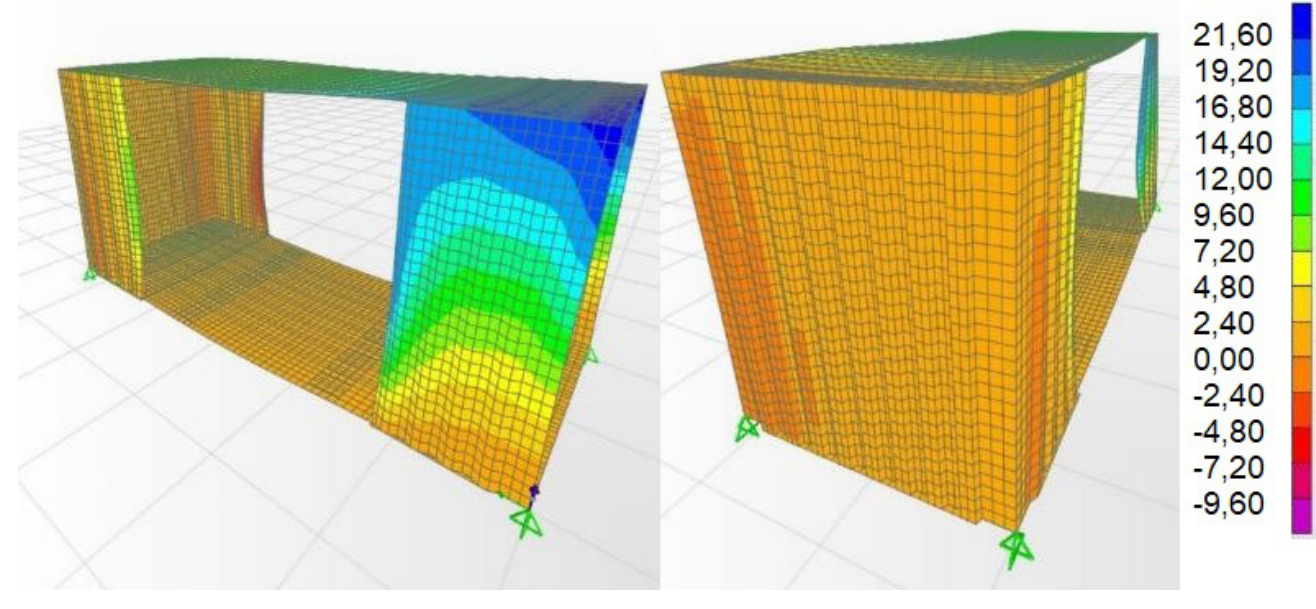

Fonte: Elaborada pelos autores.

Foram observados, também, deslocamentos verticais da ordem de $9,55 \mathrm{~mm}$, conforme mostra a Figura 14. O aumento dos deslocamentos em relação aos contêineres sem abertura indica, mais uma vez, o importante efeito estabilizante das chapas laterais, evidenciado pela piora no comportamento da estrutura mediante a supressão de parte destas chapas.

Figura 14 - Deslocamentos na direção vertical do contêiner CA-E (mm).

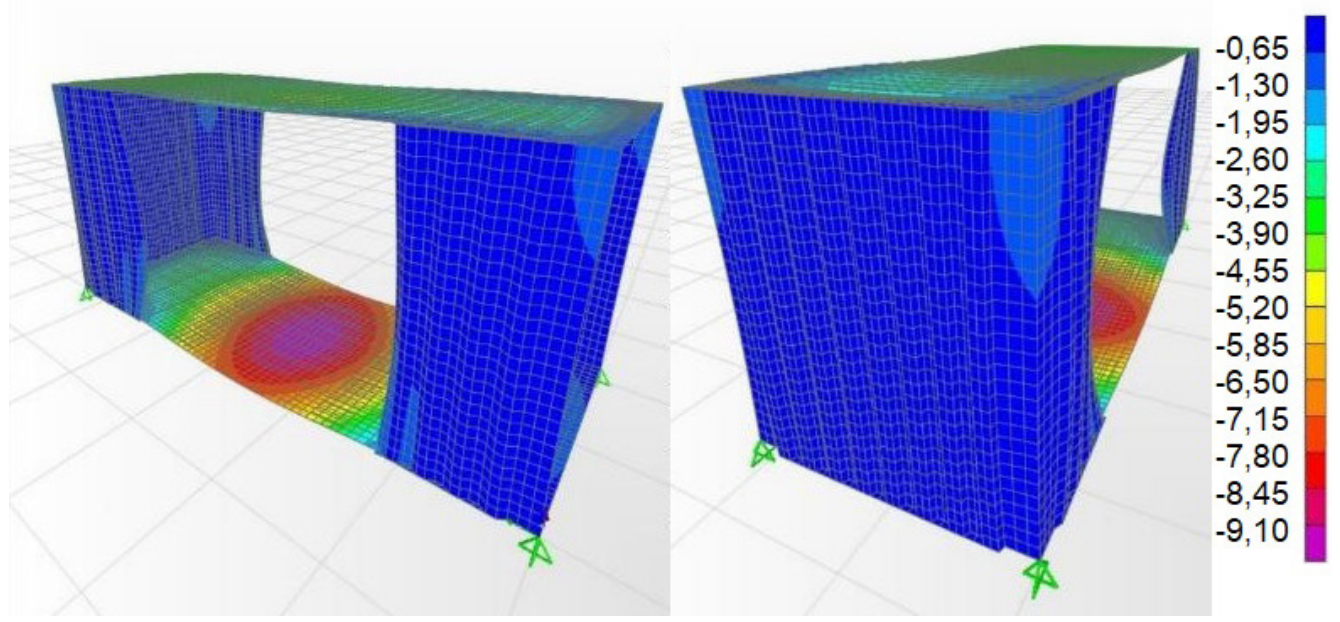

Fonte: Elaborada pelos autores.

Na região das colunas de canto foram detectadas tensões próximas de $90 \mathrm{MPa}$, enquanto nas bordas dos painéis laterais (SP), próximas às aberturas, as tensões alcançaram valores máximos próximos a 330 $\mathrm{MPa}$, de acordo com a Figura 15. Esta concentração de tensões na região da abertura é esperada, e pode indicar a necessidade de reforçar estas regiões para evitar este efeito. 
Figura 15 - Tensões de von Mises no contêiner CA-E (MPa).

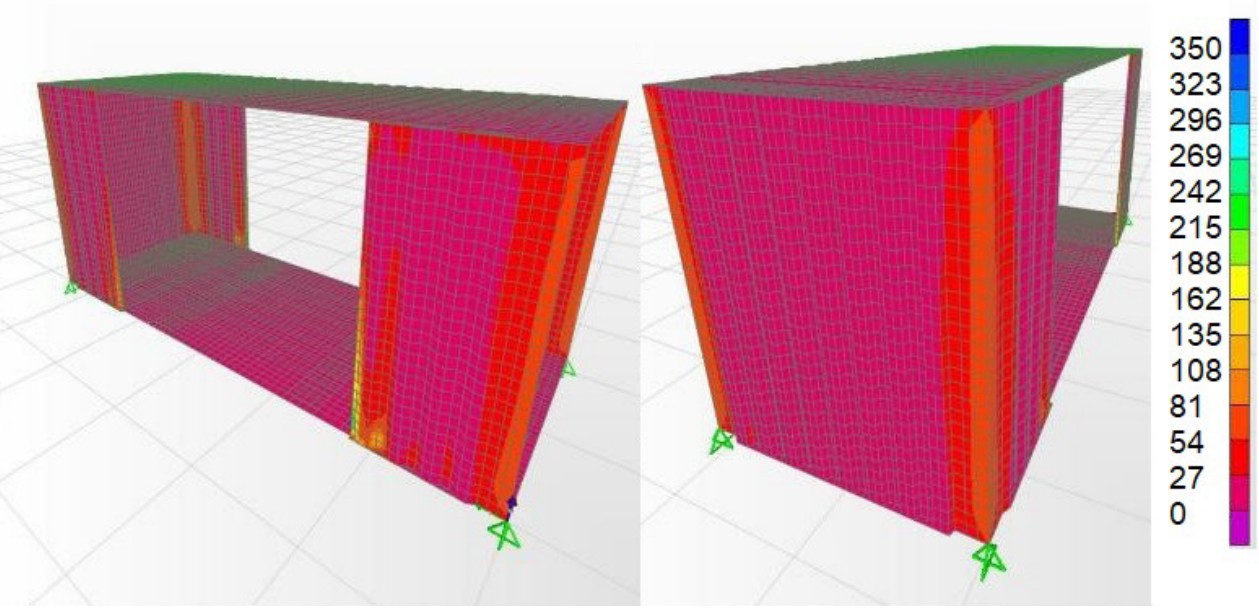

Fonte: Elaborada pelos autores.

Foram ainda determinados os esforços solicitantes nas colunas e vigas, apresentados na Tabela 10. Comparando-se aos resultados aos do contêiner sem abertura (Tabela 8), observa-se que, apesar de não haver grande variação no esforço axial das colunas, ocorre um aumento nos momentos fletores nas vigas laterais, o que indica o importante efeito da chapa trapezoidal na absorção e distribuição deste esforço. Neste caso, como nos anteriores, as solicitações e deslocamentos são inferiores aos limites estabelecidos pelas normas.

Tabela 10 - Esforços solicitantes para o contêiner CA-E.

\begin{tabular}{|c|c|c|c|c|}
\hline ELEMENTO ESTRUTURAL & C1 & $\mathrm{C2}$ & $\mathbf{C 3}$ & Normas \\
\hline \multicolumn{5}{|c|}{ ESFORÇOS AXIAIS NAS COLUNAS (kN) } \\
\hline Coluna de canto da porta (DCP) & $-266,82$ & $-270,77$ & $-270,18$ & $-482,5$ \\
\hline Coluna de canto da extremidade (ECP) & $-241,23$ & $-253,96$ & $-243,95$ & $-970,8$ \\
\hline \multicolumn{5}{|c|}{ MOMENTOS FLETORES NAS VIGAS (kN.mm) } \\
\hline Viga lateral superior (TSR) & $-367,06$ & $-937,09$ & $-617,56$ & 4635 \\
\hline Viga lateral inferior (BSR) & $-6532,88$ & $-9563,10$ & $-7355,69$ & 14523 \\
\hline \multicolumn{5}{|l|}{ DESLOCAMENTOS NAS VIGAS (mm) } \\
\hline Viga lateral inferior (BSR) & 7,55 & 8,20 & 7,95 & 17,3 \\
\hline Viga lateral superior (TSR) & 1,87 & 3,98 & 3,08 & 17,3 \\
\hline
\end{tabular}

Fonte: Elaborada pelos autores.

\section{CONTÊINER COM ABERTURAS, EM BALANÇO (CA-B)}

Neste item apresentam-se os resultados do contêiner com aberturas, apresentado no item 3.3, com o mesmo carregamento e apoios do item 4.1. O modelo apresentou deslocamentos transversais na região da porta (DH) da ordem de $33 \mathrm{~mm}$, conforme mostra a Figura 16. 
Figura 16 - Deslocamentos na direção transversal do contêiner CA-B (mm).
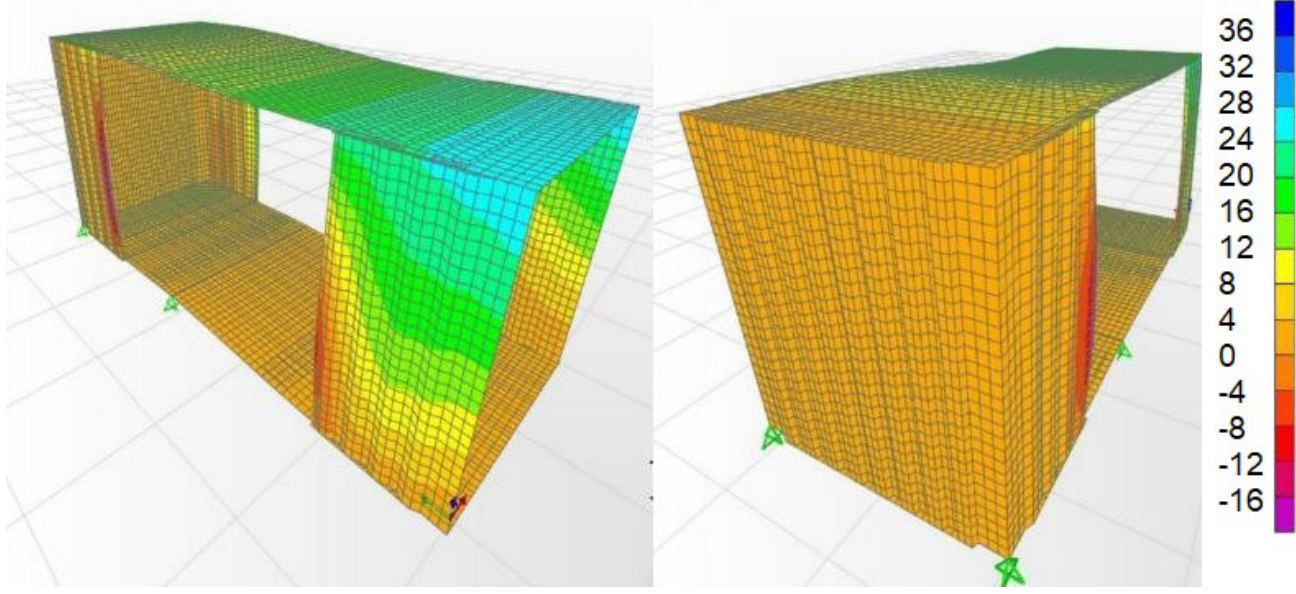

Fonte: Elaborada pelos autores.

Os deslocamentos verticais observados na região da porta atingiram $55 \mathrm{~mm}$, conforme mostra a Figura 17. Estes deslocamentos, superiores aos observados nos outros casos analisados, indicam que a redução da rigidez ocasionada pela supressão de parte das chapas, juntamente com o posicionamento do apoio fora da extremidade, leva a uma situação muito desfavorável em termos de aumento dos deslocamentos na estrutura.

Figura 17- Deslocamentos na direção vertical do contêiner CA-B (mm).
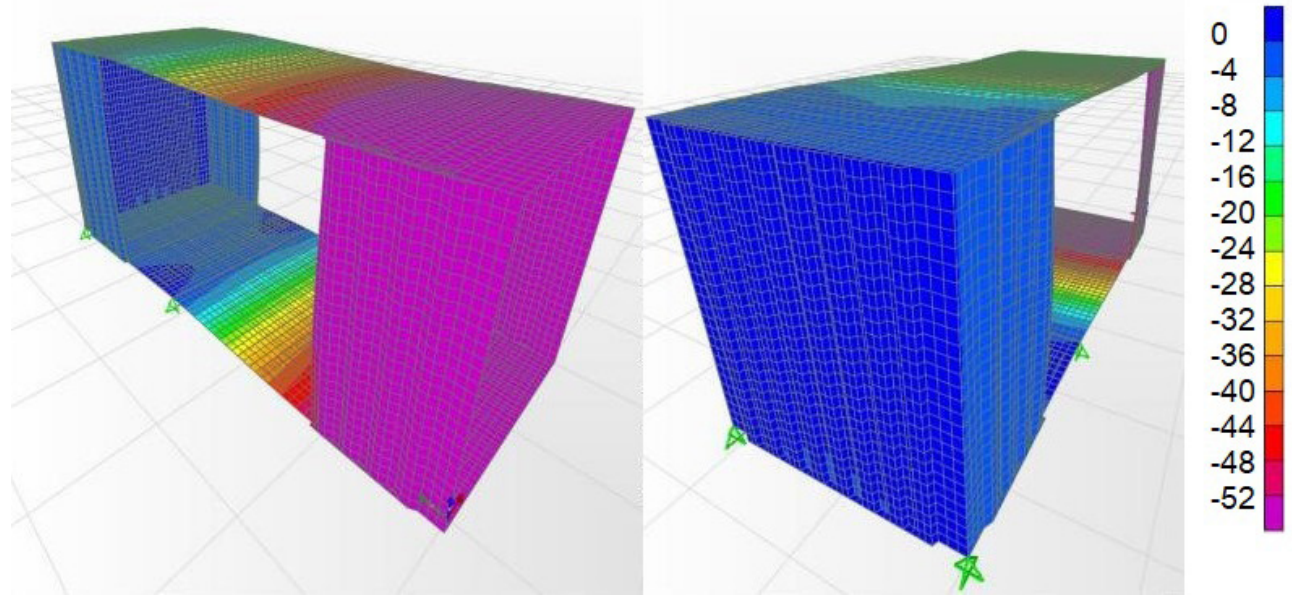

Fonte: Elaborada pelos autores.

As maiores tensões se concentraram nas bordas dos painéis laterais (SP), próximas as aberturas, com valores que atingem a tensão $350 \mathrm{MPa}$, levando ao escoamento do aço (Figura 18). Esta concentração de tensões na região das aberturas, assim como no caso CA-E, pode indicar a necessidade de reforços nesta região. De mesma forma, observam-se elevados momentos fletores e deslocamentos nas vigas laterais (Tabela 11), que excedem os limites das normas. Estes valores indicam, mais uma vez, a importância dos painéis laterais na rigidez da estrutura. 
Figura 18 - Tensões de von Mises no contêiner CA-B (MPa).

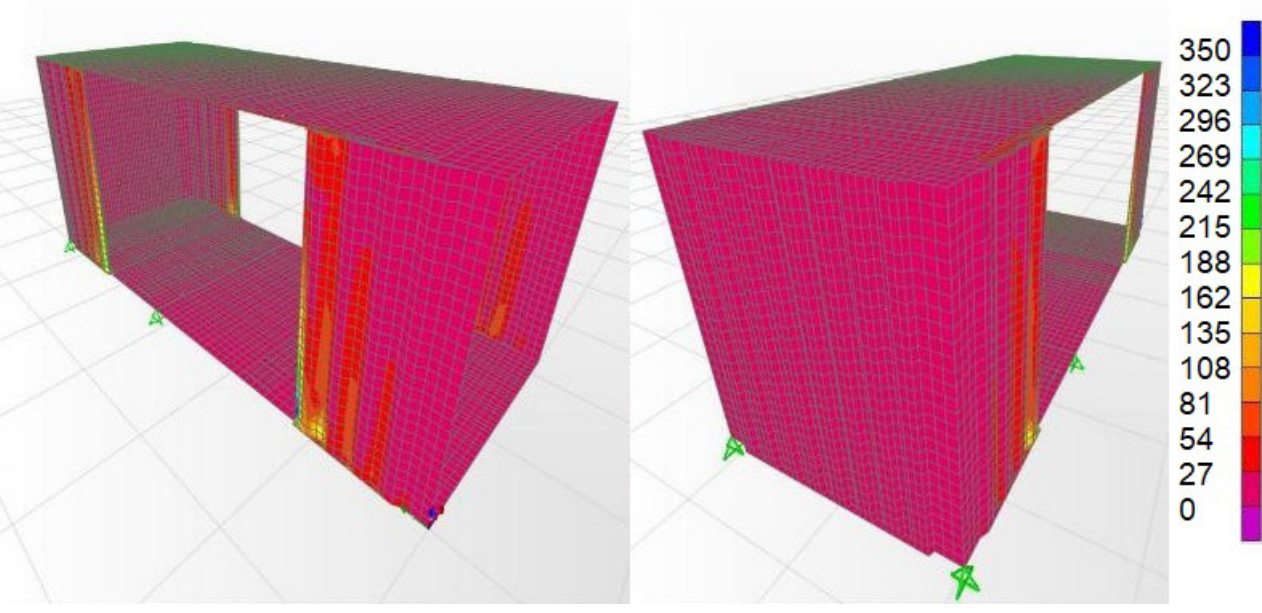

Fonte: Elaborada pelos autores.

Tabela 11- Esforços solicitantes para o contêiner CA-B.

\begin{tabular}{|c|c|c|c|c|}
\hline ELEMENTO ESTRUTURAL & $\mathrm{C} 1$ & $\mathrm{C} 2$ & $\mathrm{C} 3$ & Normas \\
\hline \multicolumn{5}{|c|}{ ESFORÇOS AXIAIS NAS COLUNAS (kN) } \\
\hline Coluna de canto da porta (DCP) & 3,97 & 5,62 & 4,32 & $-482,5$ \\
\hline Coluna de canto da extremidade (ECP) & 13,12 & 25,33 & 15,59 & $-970,8$ \\
\hline \multicolumn{5}{|c|}{ MOMENTOS FLETORES NAS VIGAS (kN.m) } \\
\hline Viga lateral superior (TSR) & $-1862,4$ & $-2878,6$ & $-2142,9$ & 4635 \\
\hline Viga lateral inferior (BSR) & $-31290,8$ & $-3359,7$ & $-35664,2$ & 14523 \\
\hline \multicolumn{5}{|c|}{ DESLOCAMENTOS NAS VIGAS (mm) } \\
\hline Viga lateral inferior (BSR) & 50,56 & 65,07 & 57,17 & 17,3 \\
\hline Viga lateral superior (TSR) & 52,58 & 67,82 & 59,53 & 17,3 \\
\hline
\end{tabular}

Fonte: Elaborada pelos autores.

\section{Conclusões}

Contêineres marítimos podem ter utilização viável na construção civil, se forem considerados aspectos arquitetônicos, de cronograma, de sustentabilidade e estruturais. Este trabalho fez uma avaliação da estrutura neste aspecto, através da simulação da estrutura via elementos finitos.

A análise desenvolvida mostrou-se adequada, levando a resultados coerentes e que permitiram a avaliação da estrutura considerando diferentes condições de apoio e de aberturas em suas faces.

Observou-se que os contêineres sem aberturas significativas e apoiados em suas extremidades têm comportamento estrutural adequado se utilizados na construção civil, uma vez que estão submetidos a carregamentos inferiores aos de sua utilização na cadeia logística. Quando empregados em balanço ainda assim apresentam resposta estrutural satisfatória.

O emprego de aberturas laterais muda este quadro, induzindo grandes deslocamentos, esforços e tensões na estrutura, estando ela apoiada e principalmente quando em balanço. Isto indica que quando a arquitetura impõe estas aberturas seria necessário o emprego de reforços para a garantia do bom fun- 
Souza et al.

cionamento do contêiner sob o aspecto estrutural.

\section{Agradecimentos}

Os autores deste trabalho agradecem ao Mestrado profissional em Engenharia das Construções (ME$\mathrm{CON}$ ) da Universidade Federal de Ouro Preto pelo suporte a esta pesquisa.

\section{REFERÊNCIAS}

ARCHDAILY, Casa Container Granja Viana / Container Box. Disponível em: http://www.archdaily.com. br/br/800283/casa-container-granja-viana-container-box. Acesso em: 06 dez. 2016.

ASSOCIAÇÃO BRASILEIRA DE NORMAS TÉCNICAS.NBR 6120: Cargas para o cálculo de estruturas de edificações. Rio de Janeiro, 1980.

ASSOCIAÇÃO BRASILEIRA DE NORMAS TÉCNICAS. NBR 6123: Forças devidas ao vento em edificações. Rio de Janeiro, 1988. 66p.

ASSOCIAÇÃO BRASILEIRA DE NORMAS TÉCNICAS. NBR 7190: Projeto de estruturas de madeira. Rio de Janeiro, 1997. 107p.

ASSOCIAÇÃO BRASILEIRA DE NORMAS TÉCNICAS. NBR 8800: Projeto de estruturas de aço e de estruturas mistas de aço e concreto de edifícios. Rio de Janeiro, 2008. 237p.

ASSOCIAÇÃO BRASILEIRA DE NORMAS TÉCNICAS.NBR 14762: Dimensionamento de Estruturas de Aço Constituídas por Perfis Formados a Frio. Rio de Janeiro, 2010. 87p.

BELLEI, I. H.; PINHO, F. O.; PINHO, M. O. Edifícios de múltiplos andares em aço. 2. ed. São Paulo: Pini, 2008. 557p.

BEBIANO R.; PINA P.; SILVESTRE N.; CAMOTIM D. GBTUL - Buckling and vibration analysis of Thin-Walled Members, Departamento de Engenharia Civil, Universidade Técnica de Lisboa, 2008.

BERNARDO, L. F. A.; OLIVEIRA, L. A. P.; NEPOMUCENO, M. C. S.; ANDRADE, J. M. A. Use of refurbished shipping containers for the construction of housing buildings: details for the structural project. Journal of Civil Engineering and Management. v.19, n.5, p. 628-646, 2013. doi: 10.3846/13923730.2013.795185

CASA CLÁUDIA, Hostel feito de contêineres é inspirado no jogo Tetris. Disponível em:http://casa. abril.com.br/materia/hostel-feito-de-conteiners-e-inspirado-no-jogo-tetris. Acesso em: 28 nov. 2016.

CSI, CSI Analysis Reference Manual for SAP2000, ETABS and SAFE. Computers and Structure, Inc., Berkeley, 2007.

GIRIUNAS, K.; SEZEN, H.; DUPAIX, R. B. Evaluation, modeling and analysis of shipping container building structures. Engineering Structures, v. 43, p. 48-57, 2012. 
HAPAG-LLOYD, Container Specification. Disponível em: http://www.hapag-lloyd.com. Acesso em: 06 abr. 2016.

HONG, Y. A study on the condition of temporary housing following disasters: Focus of container housing. Frontiers of Architectural Research. v. 6, n. 3, p. 374-383, 2017. https://doi.org/10.1016/j.foar.2017.04.005

INHABITAT, The Box Office recycles 32 shipping containers into 12 colorful offices in Providence. Disponível em: <http://inhabitat.com/the-box-office-recycles-32-shipping-containers-into-12-colorful-offices-in-providence/the-box-office-distill-studio-7/>. Acesso em: 25 nov. 2016 .

INHABITAT, Müvbox Fast Food Container Restaurant. Disponível em: http://inhabitat.com/muvbox-fast-food-shipping-container-restaurant/. Acesso em: 29 de nov. 2016 b.

INTERNATIONAL ORGANIZATION FOR STANDARDIZATION. ISO 668: Series 1 freight containers - Classification, dimensions and ratings. Genebra, 2013. 17p.

INTERNATIONAL ORGANIZATION FOR STANDARDIZATION. ISO 1496-1: Series 1 freight containers - Specification and testing - Part 1: General cargo containers for general purposes. Genebra, 2013. 28p.

INTERNATIONAL ORGANIZATION FOR STANDARDIZATION. ISO 6346: Freight containers - Coding, identification and marking. Genebra, 1995.23p.

MARQUES, A. R. A. Estudo de coordenação modular em projetos de reciclagem de contentores. Covilhã: Universidade da Beira Interior, 2011.

MILANEZE, G. L. S.; BIELSHOWSKY, B. B.; BITTENCOURT, L. F.; SILVA, R.; MACHADO, L. T. A utilização de containers como alternativa de habitação social no município de Criciúma/SC. Revista Técnico Científica do IFSC. v.3, n.1, p. 615-624, 2012.

RESIDENTIAL SHIPPING CONTAINER PRIMER, Shipping container structural components and terminology. Disponívelem: http://www.residentialshippingcontainerprimer.com/CONTAINER COMPONENTS AND TERMINILOGY. Acesso em: 06 de abr. 2016.

ROMANO, L.; PARIS, S. R.; NEUENFELDT JR. A. L. Retrofit de contêineres na construção civil. Labor e Engenho, v.8, n.1, p.83-92, 2014. https://doi.org/10.20396/lobore.v8i1.225/

SILVA, R. D. F. Construção com contentores marítimos remodelados: estudo de casos de aplicação. Covilhã: Universidade da Beira Interior, 2010.

SMITH, R. E. Prefab architecture: a guide to modular design and construction. Nova Jersey: John Wiley\& Sons Inc., 2010.

SPILLMANN ESCHLE ARCHITEKTEN, Freitag flagship Zurich. Disponível em: http://www.spillmannechsle.ch/wp/?p=140. Acesso em: 25 nov. 2016.

ZHANG, G.; SETUNGE, S.; VAN ELMPT, S. Using shipping containers to provide temporary housing 
in post-disaster recovery: Social case studies. Procedia Economics and Finance, v. 18, 618 - 625, 2014. doi: 10.1016/S2212-5671(14)00983-6.

ZOMER, C. D. O sol: caminho para sustentabilidade energética de uma casa container. - Concurso Catarinense de Monografias sobre Eficiência Energética, Florianópolis: Instituto Ideal, 2009. 